\title{
EXERCISE-INDUCED REVERSAL OF AGE-RELATED DECLINES OF OXIDATIVE REACTIONS, MITOCHONDRIAL YIELD, AND FLAVINS IN SKELETAL MUSCLE OF THE RAT*
}

\author{
ROBERT E. BEYER**, JOSEPH W. STARNES***, DEE W. EDINGTON, \\ RICHARD J. LIPTON, RALPH T. COMPTON, III and \\ MICHAEL A. KWASMAN \\ Laboratory of Chemical Biology, Department of Cellular and Molecular Biology, Division of Biological \\ Sciences, and The Department of Kinesiology, The University of Michigan, Ann Arbor, MI 48109 (U.S.A.)
}

(Received April 15th, 1983)

\section{SUMMARY}

The ability of gastrocnemius muscle homogenates to catalyze the oxidation of succinate, glutamate + malate, pyruvate + malate, palmitoyl-coenzyme A, decanoylcarnitine and palmitoylcarnitine in the presence of ADP decreased by approximately $32 \%$ in sedentary male Sprague-Dawley rats between the ages of 9 and 25 months. Following 21 weeks of treadmill training (running), such homogenates from 25 -month-old animals catalyzed oxidations $55 \%$ more rapidly than those from 25 -month-old sedentary rats, and $17 \%$ faster than those from 9-monthold sedentary rats. Total and peptide-bound flavin of gastrocnemius muscles also declined between 9 and 25 months of age and were elevated in the 25-month-old endurance trained rats to levels greater than both 9- and 25-month-old sedentary animals. The yield of protein in the mitochondrial fraction from the quadriceps femoris muscle decreased between 9 and 25 months and was restored to the 9-month level by endurance training. The kinetic characteristics of the isolated mitochondria were not influenced by age or exercise. These data indicate that

Key words: Flavin; Aging; Endurance training; Fatty acid oxidation; Succinoxidase; Muscle metabolism; Mitochondria; Oxidative phosphorylation; Muscle protein

\footnotetext{
-Portions of this study were reported at the 35th Annual Meeting of The Gerontological Society of America, Boston, Massachusetts. November 21 st, 1982.

* To whom correspondence should be directed.

*** Present address: Department of Biochemistry and Biophysics, University of Pennsylvania, School of Medicine, Philadelphia, PA 19104, U.S.A.
} 
2-year-old rats retain the capacity to increase skeletal muscle oxidative capacity and mitochondrial population density in response to endurance training.

\section{INTRODUCTION}

It is generally acknowledged that the physical performance capacity of animals, including humans, decreases during the middle and later years of life. This is accompanied by, and is a reflection of, a decline with age of the maximum oxygen consumption of the intact animal [1]. Aging is also accompanied by a gradual diminution of energy yielding reactions and related metabolic functions in several organs, including skeletal muscle [2]. While a number of workers have noted decreased activities of several enzymes involved in energy metabolism with aging, it has been suggested [3], "that the decrease in maximal oxygen uptake and muscular strength in aging humans probably can not be explained in terms of a deteriorating skeletal muscle energy metabolism." It is our contention that such deterioration is a major factor contributing to the decrease in aerobic capacity in the elderly.

Although it is clear that many of the changes which occur in skeletal muscle of young animals in response to a program of endurance training involve the supporting connective tissue proteins [4] and enzymes of oxidative pathways of energy metabolism [5], very little information is available presently on the response of energy releasing and conserving pathways to endurance exercise in the aged animal. Some information has appeared which indicates that exercise applied selectively and at appropriate periods of the life span can affect longevity in the laboratory rat [6,7]. However, as Shock has pointed out [8], "Although there is ample evidence that age influences exercise performance, data are not available at present to determine the effect of exercise on ageing -or rate of ageing."

So as to clarify the controversy regarding the potential of exercise to restore the metabolic capabilities of skeletal muscle in the aged, we have determined the concentrations of flavin in, and the overall rates of oxidation of substrates for fatty acid and amino acid oxidations, the citric acid cycle, and electron transport chain activities catalyzed by gastrocnemius muscle from 9- and 25-month-old sedentary rats and 25-month-old endurance trained and weight controlled rats. Muscle homogenates, instead of mitochondria, were used to study reaction rates and component concentrations since we were interested in studying the capacity of the whole muscle to change with age and adapt to exercise. In addition, isolated mitochondria were also assayed since we $[9,10]$ and others $[11,12]$ have reported that although more mitochondria may be isolated from muscle of endurance trained than sedentary animals, the kinetic characteristics of the two preparations do not differ except for enzymes of the beta-oxidation of fatty acids, the activities of which are diminished in mitochondria of aged rats [13]. 


\section{METHODS}

\section{Animal care and training}

Retired breeder Sprague-Dawley rats, designated $\mathrm{Crl}: \mathrm{COBS}^{[R]} \mathrm{CD}^{[\mathrm{R}]}(\mathrm{SD})$, were obtained from Charles River Breeding Laboratories, Portage, MI, at 8-10 n:onths of age and housed singly in the Animal Care Facility of the Division of Biological Sciences in a room segregated from other species and maintained on a 12-h light-dark cycle. Except for the weight control group described below, all animals received Purina Laboratory Rat Chow and water ad libitum. In our colony of 120 rats, 102 survived to 25 months of age. Four groups of animals, selected from our aging colony, were used: (1) 9-month-old sedentary (Sed-9), (2) 24-26-month-old sedentary (Sed-25), (3) 24-26-month-old endurance trained (Tr-25), and (4) 24-26month-old food restricted weight controls (Wt-25). Since it was our intent to study the interaction of age and exercise, animals which showed pathology or unexplained weight loss were excluded from participation in these experiments.

The exercise training protocol was similar to that described previously [14]. A group of 21-month-old rats was introduced into a protocol consisting of running 5 days per week for 21 weeks in a ten-channel, motor driven treadmill. During the entire training period the rats ran at an incline angle of $8^{\circ}$ and the ambient temperature of the training room was maintained at $19^{\circ} \mathrm{C}$. The rats were run for $10 \mathrm{~min}$ at $11 \mathrm{~m} / \mathrm{min}$ during the first week after which, on each succeeding session for the next 2 weeks, the duration and speed were increased to $12 \mathrm{~min}$ at $25 \mathrm{~m} / \mathrm{min}$. The duration and speed were increased over the next 6 weeks until the rats were running for $27 \mathrm{~min}$ at $25 \mathrm{~m} / \mathrm{min}$. Because some of the elderly rats appeared to have difficulty maintaining a rate of $25 \mathrm{~m} / \mathrm{min}$ over the entire exercise period, the time was decreased to $25 \mathrm{~min}$ for the next 4 weeks. The final 6 weeks of training consisted of $30 \mathrm{~min}$ per day at $25 \mathrm{~m} / \mathrm{min}$.

Since, in our experience, the body weight of elderly endurance trained rats of this strain is lower than in sedentary animals of the same age, an additional control group was prepared in which the body weights of the nontrained animals were maintained at the same weights as the trained individuals. This was accomplished by monitoring and regulating the food intake of the weight control sedentary group.

\section{Preparation of homogenates}

Animals were anaesthetized with sodium pentobarbital $(40 \mathrm{mg} / \mathrm{kg}$, i.p.), decapitated and exsanguinated. The lower hind leg muscles were removed, freed of the plantaris and soleus muscle and the gastrocnemius and the quadriceps femoris muscle group cooled in ice-cold homogenizing medium ( $50 \mathrm{mM} \mathrm{TES}{ }^{*}$, $100 \mathrm{mM} \mathrm{KCl}, 0.5 \mathrm{mM} \mathrm{MgSO}_{4}, 1 \mathrm{mM}$ EDTA, $5 \mathrm{mM} \mathrm{K.PO}$ ) at $\mathrm{pH} 7.5$ [15]. The tissue was maintained at $0-4^{\circ} \mathrm{C}$ during all subsequent manipulations until used for

" $N$-tris(hydroxymethyl)methyl-2-aminoethanesulfonic acid. 
assay. After wet weights were recorded, the gastrocnemius muscles were rinsed several times with cold homogenizing medium, minced, and maccerated for $90 \mathrm{sec}$ in homogenizing medium ( $7 \mathrm{ml} / \mathrm{g}$ wet weight) with a Willem's Ultra-Turrax homogenizer (model BEW, Janke and Kunkel AB) set at half speed. The suspension was then homogenized in a motor-driven Potter-Elvehjem PTFE-glass homogenizer (medium fit) for 8-10 strokes and filtered through two layers of cheese cloth. Filtered particulate matter was examined and rehomogenized, if necessary, to ensure total extraction. In order to lower the concentration of endogenous substrates, homogenates were centrifuged at $73 \times 10^{4} \mathrm{~g} / \mathrm{min}$. The resulting pellet was suspended to the original volume with homogenizing medium and sedimented again with the same force. The final pellet was suspended in homogenizing medium at a protein concentration of $25 \mathrm{mg} / \mathrm{ml}$ and used for assay of rates of oxidation.

\section{Preparation of mitochondria}

Mitochondria were isolated from the quadriceps femoris muscle group according to the procedure of Makinen and Lee [16] except that the muscle was homogenized for $30 \mathrm{sec}$ with a Willem's Polytron, model BEW, rotating at a speed of $14500 \mathrm{rpm}$ while unloaded as described by Beyer and MacDonald [17].

\section{Electron microscopy}

Several individual mitochondrial preparations were examined for purity and integrity with the electron microscope according to Kuner and Beyer [18]. Upon completion of kinetic measurements with the oxygen electrode, the mitochondrial suspension was removed from the reaction cuvette and $100 \mu \mathrm{l}$ centrifuged at approximately $10800 \mathrm{~g}$ for $30 \mathrm{sec}$ in a Coleman model 6-8111 microcentrifuge which accelerates to its maximum speed within $2 \mathrm{sec}$. The supernatant fraction was removed and quickly replaced with fixative $(2 \%$ osmium tetroxide in $0.15 \mathrm{M}$ sucrose-25 mM Tris- $\mathrm{HCl}, \mathrm{pH} 7.5$ ). The period between sampling and fixation was approximately $\mathbf{4 0} \mathrm{sec}$. The mitochondrial sample was maintained in the fixative for $1 \mathrm{~h}$ at $0^{\circ} \mathrm{C}$, removed and dehydrated in increasing concentrations of ethanol, and embedded in a soft epoxy-resin mixture consisting of 4 parts Epon 812 (Shell), 10 parts dodecenylsuccinic anhydride, and 0.32 parts 2,4,6-tri(dimethylaminomethyl)phenol (DMP-30). The blocks were sectioned with glass knives on a Porter-Blum ultramicrotome, sections picked up on 300-mesh, uncoated copper grids (Fullman), and stained in $4 \%$ uranyl acetate in $40 \%$ ethanol for $40 \mathrm{~min}$ at room temperature. Electron micrographs were obtained on DuPont Cronar Ortho A Litho COA7 film with an RCA-EMU 4 electron microscope operating at $50 \mathrm{kV}$.

Assays

The protein concentration of homogenates was determined by a biuret procedure [19] modified by developing the blue copper-peptide bond complex in 
$30 \mathrm{sec}$ at $100^{\circ} \mathrm{C}$. In more recent experiments the procedure of Beyer [20] has been used in order to avoid turbidity, due to fatty tissues in aged rats, in the biuret assay. Crystalline bovine serum albumin, used as standard, was prepared and standardized according to Kaziro et al. [21]. Mitochondrial protein was assayed with either the procedure of Lowry et al. [22] or that of Watters [19].

Rates of substrate oxidations catalyzed by homogenates were determined essentially as described previously [23] with Clark type electrodes and the circuit described by Estabrook [24]. Experimental and control preparations were assayed simultaneously by employing two all-glass cuvettes thermostated at $37^{\circ} \mathrm{C}$ in series and recording signals from the two electrodes on a Varian 161A dual channel recorder. The final volume of the cuvette contents was $1.8 \mathrm{ml}: 1.6 \mathrm{ml}$ of incubation medium $\left(0.13 \mathrm{M} \mathrm{KCl}, 20 \mathrm{mM} \mathrm{K}^{\circ} \mathrm{PO}_{4}, \mathrm{pH} \mathrm{7.2)}\right.$ and $0.2 \mathrm{ml}$ of homogenate to yield a final protein concentration of $2.78 \mathrm{mg} / \mathrm{ml}$. Substrates and their final concentrations were: glutamate $(11.1 \mathrm{mM})$, succinate $(11.1 \mathrm{mM})$, pyruvate-malate $(11.1 \mathrm{mM}-$ $1.1 \mathrm{mM})$, palmitoyl-coenzyme A $(11.1 \mu \mathrm{M})$, palmitoylcarnitine-malate-albumin $(66.7 \mu \mathrm{M}-1.1 \mathrm{mM}-88.9 \mu \mathrm{M})$ and decanoylcarnitine-albumin $(0.22 \mathrm{M}-88.9 \mu \mathrm{M})$. The concentration of oxygen was assumed to be $0.199 \mathrm{mM}$ at $37^{\circ} \mathrm{C}$ [25]. Reactions were started by the addition of substrate to the cuvette. The rate was recorded and $250 \mathrm{nmol}$ of ADP were added in $10 \mu \mathrm{l}$ to obtain the rate of state 3 oxidation. Addition of cofactors such as cytochrome $c$ and $\mathrm{NAD}^{+}$did not enhance the ADP-stimulated rate of respiration and were not used generally in the measurement of oxygen consumption.

Oxidations catalyzed by mitochondrial enzymes were assayed at $25^{\circ} \mathrm{C}$ as described above for homogenates in a medium $0.15 \mathrm{M}$ in sucrose, $0.025 \mathrm{M}$ in Tris- $\mathrm{HCl}$, and $6 \mathrm{mM}$ in inorganic orthophosphate, $\mathrm{pH} 7.5$. States 3 and 4 respiration, the respiratory control ratio (RCR) and the ADP/O ratio were calculated as described by Chance and Williams [26]. ADP was added to the reaction as $10 \mu \mathrm{l}$ of a $42.2 \mathrm{mM}$ solution and was assayed enzymatically [27]. The concentration of oxygen at $25^{\circ} \mathrm{C}$ was assumed to be $0.237 \mathrm{mM}$ [25].

Skeletal muscle flavin was assayed according to the method of Rao et al. [28] using whole homogenates of gastrocnemius muscle.

\section{Statistical evaluation}

Inferences with regard to the significance of differences between any two groups of data were made using Student's small sample analysis for the calculation of $t$ values and a two-tailed comparison of $p$.

\section{RESULTS}

\section{Body weight}

The group of rats participating in the exercise program lost $10 \%$ of their body weight during the first 7 weeks of the program $(p<0.001, n=36)$ after which their weights remained relatively stable (Fig. 1). At the end of the 21 weeks of 


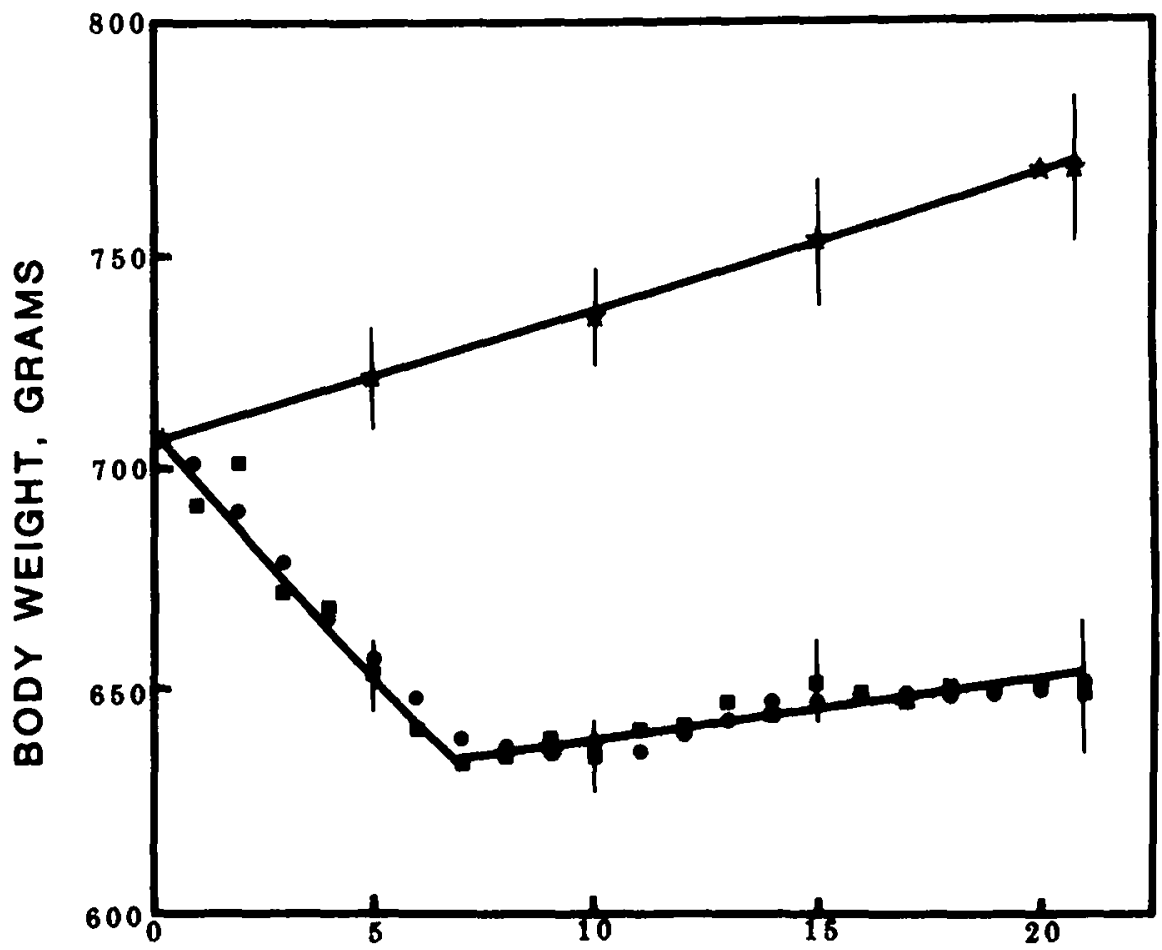

EXERCISE OR FOOD RESTRICTION, WEEKS

Fig. 1. Body weights of sedentary $(\star)$, exercised $(W)$, and food-restricted $(O)$ rats. The food restriction and exercise programs were started when the rats were 21 months of age and continued for 21 weeks. Vertical lines represent the standard error of the mean for Sed-25 and Tr-25 groups.

exercise the rats in the trained group weighed $16.1 \%$ less than the age-matched controls $(p<0.001, n=32)$ (Fig. 1). The continued weight gain of this strain of Sprague-Dawley rat [Crl:COBS $\left.{ }^{[R /} C^{(R)}(S D)\right]$ over the life span has been documented previously $[29,12]$.

\section{Rates of homogenate catalyzed oxidations}

Table I contains mean values of the rates of oxidation catalyzed by gastrocnemius muscle homogenates from four groups of rats oxidizing six substrates in the presence of ADP. The rates of oxidation catalyzed by homogenates from the 25-month-old endurance trained rats ( $\mathrm{Tr}-25)$ were significantly greater than those from age-sedentary controls (Sed-25) and age-weight matched controls (Wt-25) with all substrates tested and greater than those from 9-month-old sedentary rats (Sed-9) with palmitoylcarnitine and pyruvate-malate as substrates. A trend toward a loss of oxidative capacity in the gastrocnemius muscle between 9 and 25 months in sedentary animals is apparent although statistical significance $(p<0.05)$ was observed only with succinate as substrate. When Sed-9 was compared to the Wt-25 group, however, the loss of oxidative capacity was statistically significant with all substrates except palmitoylcarnitine. 

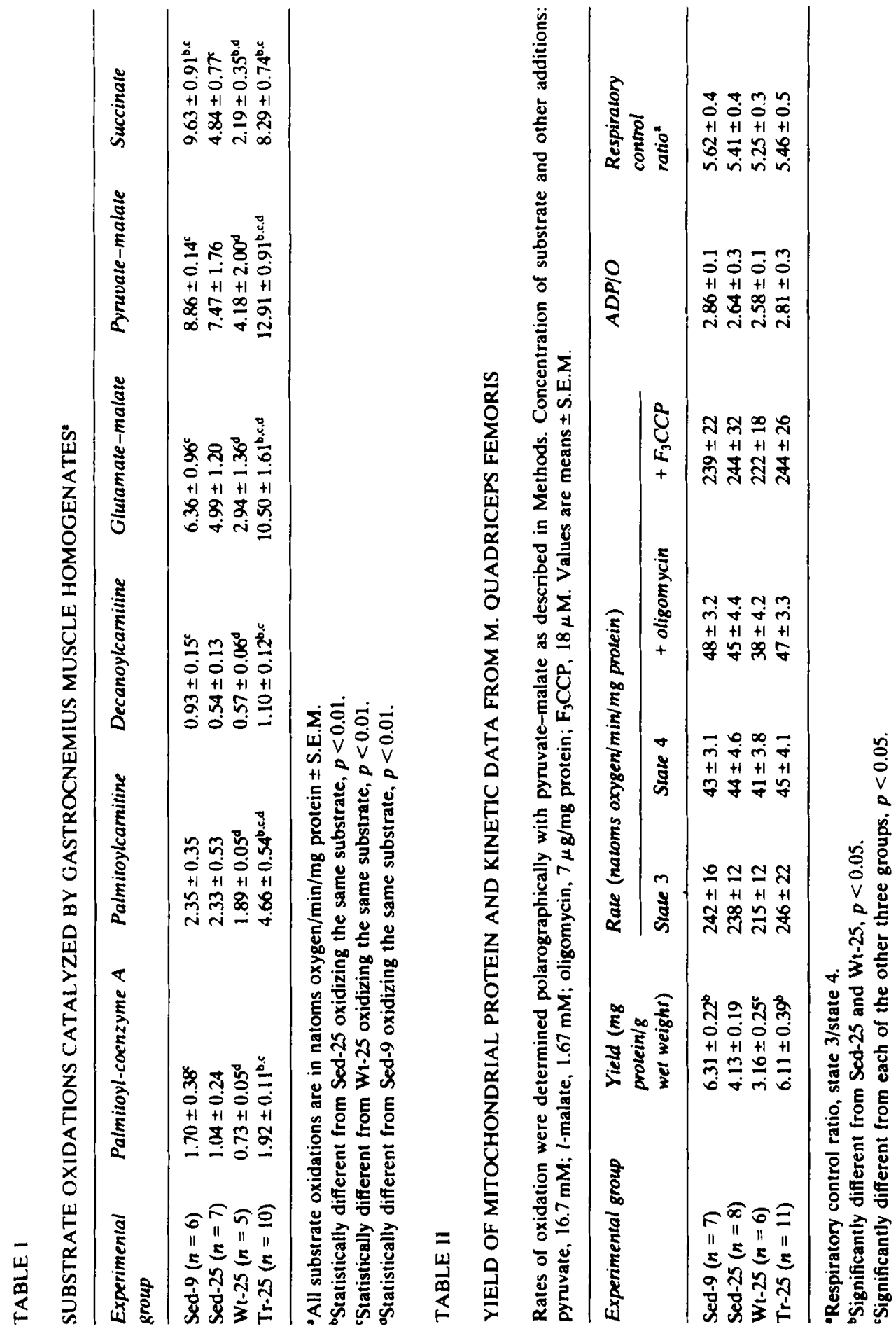


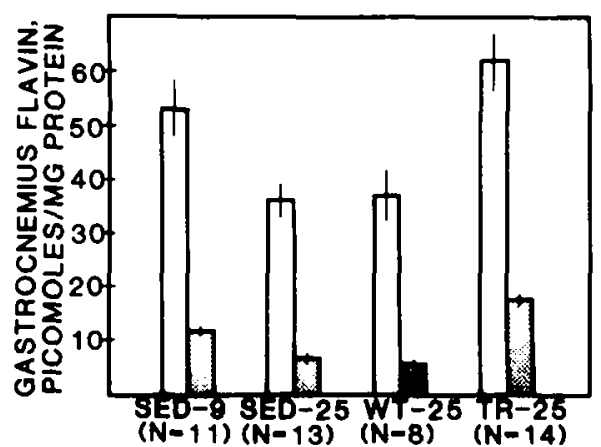

Fig. 2. Flavin levels of gastrocnemius muscles from 25-month-old sedentary (Sed-25), food restricted (Wt-25), endurance trained (Tr-25) and 9-month-old sedentary (Sed-9) rats. Open columns: total flavin. Stippled columns: peptide-bound flavin. Range markers indicate S.E.M. For total flavin the difference between Sed-9 and Sed-25 groups is significant $(p<0.01)$; between Sed-25 and Tr-25 significant $(p<0.001)$; between Tr-25 and Wt-25 significant $(p<0.05)$. For peptide-bound flavin the difference between Sed-9 and Sed-2S is significant $(p<0.001)$; between Sed-25 and Wt-25 significant $(p<0.05)$; between Tr-25 and Sed-25 significant $(p<0.001)$; between Tr-25 and Sed-9 significant $(p<0.001)$.

\section{Flavin levels}

Figure 2 contains data on the concentration of total and peptide-bound flavins from gastrocnemius muscles of the same groups of rats for which oxidative data were obtained and reported in Table I. Total flavin decreased between 9 and 25 months of age in gastrocnemius muscles (Sed-9 vs. Sed 25, $p<0.02$ ) while 21 weeks of endurance training increased total flavin when compared to age-matched sedentary animals $(p<0.001)$ and age-matched weight controls $(p<0.05)$ to levels not significantly different than those of 9 -month-old sedentary animals. Peptidebound, trypsin-released flavin, the prosthetic group of succinate dehydrogenase [30], followed a similar pattern except for the difference between the Sed-25 and Wt-25 groups which was significant $(p<0.05)$ for peptide-bound flavin.

\section{Mitochondrial yield and oxidations}

The yield of mitochondria from the quadriceps femoris muscle declined $35 \%$ between 9 and 25 months (Sed-9 to Sed-25) and increased 100\% in the endurance trained rat compared to their weight matched controls (Tr-25 vs. Wt-25) (Table II). Dietary restriction in the 25-month-old sedentary rat (Wt-25) resulted in a greater loss of mitochondrial protein compared to sedentary animals of the same age allowed food ad libitum (Wt-25 vs. Sed-25, $p<0.05$ ). This is consistent with the generally lower rates of oxidation catalyzed by tissues and peptide-bound flavin from the food-restricted group (Table I and Fig. 2).

Analysis of the kinetic properties of the mitochondria isolated from quadriceps femoris muscles of all four groups strongly indicates that such mitochondria are indistinguishable between the groups (Table II) despite reasonably low values for the standard error of the means. The data in Table II also indicate that mitochondria isolated from each of the four groups yield kinetic 
values in the range of those previously published [31] for skeletal muscle mitochondria oxidizing pyruvate-malate under phosphorylating (+ADP, state 3), uncoupled $\left(+\mathrm{F}_{3} \mathrm{CCP}{ }^{*}\right)$, and ADP-limited (state 4) states and in the presence of oligomycin (an inhibitor of oxidative phosphorylation). In addition, the derived values for the respiratory control ratios and the efficiency of oxidative phosphorylation (ADP/O) are within normal limits for skeletal muscle mitochondria [32] for all four groups of animals. Figure 3 consists of an electron micrograph of mitochondria isolated from the quadriceps femoris of one of the 25-month-old sedentary animals and demonstrates structural integrity and a low degree of

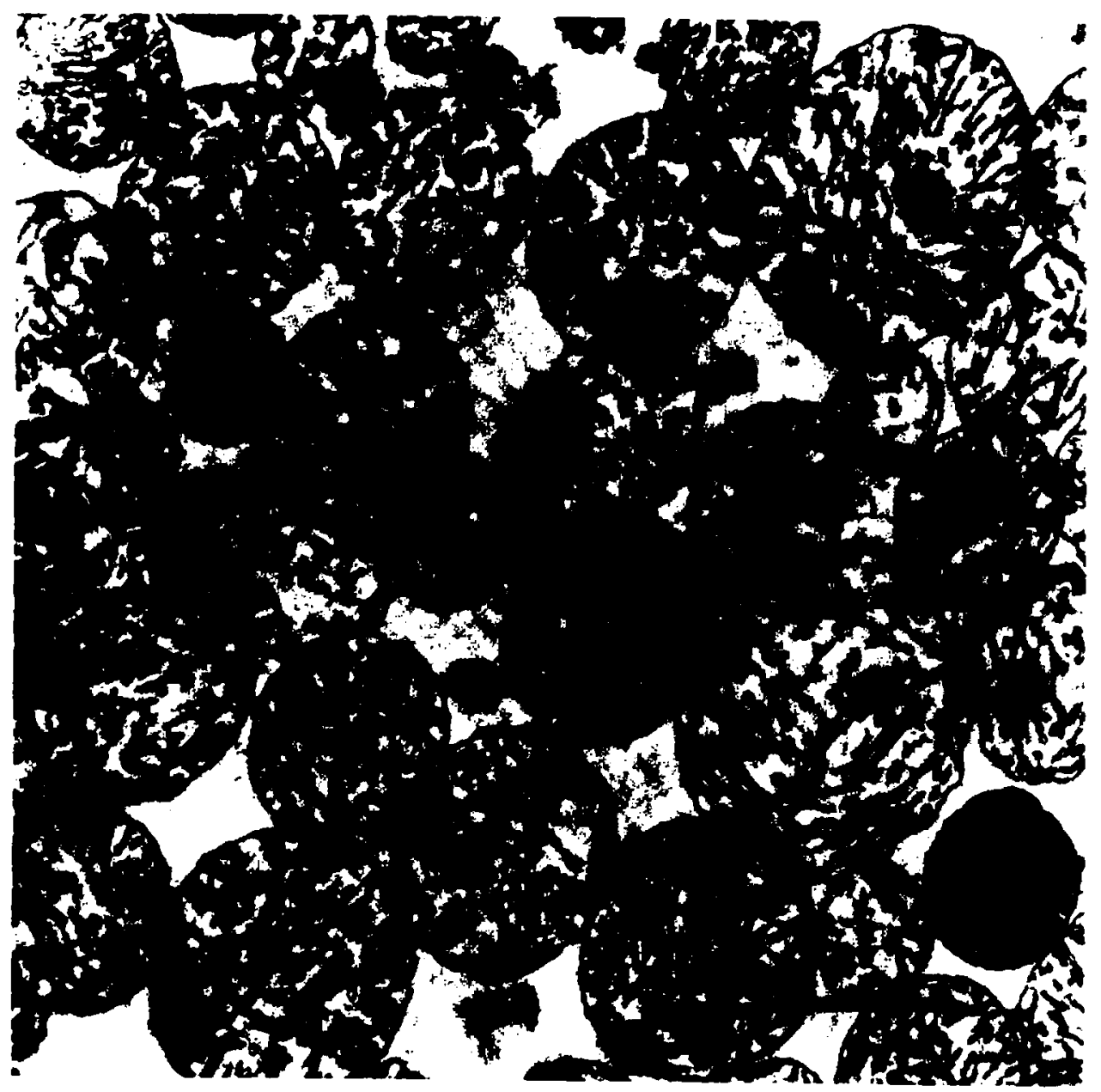

Fig. 3. Electron micrograph of isolated rat quadriceps femoris muscle mitochondria in the orthodox configuration. Scale indicator $=1 \mu \mathrm{m}$; magnification $\times 160000$.

*p-Trifluoromethoxycarbonylcyanidephenylhydrazone. 
TABLE III

GASTROCNEMIUS MUSCLE WEIGHTS AND PROTEIN YIELDS WITH AGE AND EXERCISE:

\begin{tabular}{llll}
\hline $\begin{array}{l}\text { Experimental } \\
\text { group }\end{array}$ & $\begin{array}{l}\text { Gastrocnemius } \\
\text { weights }(8)\end{array}$ & $\begin{array}{l}\text { Total protein } \\
(\mathrm{mg})\end{array}$ & $\begin{array}{l}\text { Percentage } \\
\text { protein }\end{array}$ \\
\hline Sed-9 $(n=8)$ & $4.842 \pm 0.058^{\mathrm{b}}$ & $689.9 \pm 29.2^{\mathrm{b}}$ & $14.2 \pm 0.47$ \\
Sed-25 $(n=7)$ & $4.162 \pm 0.321$ & $794.2 \pm 39.9$ & $19.1 \pm 0.47$ \\
Wt-25 $(n=7)$ & $3.246 \pm 0.083^{\mathrm{d}}$ & $669.1 \pm 18.3^{\mathrm{d}}$ & $20.7 \pm 0.57^{\mathrm{c}}$ \\
Tr-25 $(n=8)$ & $4.927 \pm 0.232^{\mathrm{e} .1}$ & $795.5 \pm 33.3^{\mathrm{s}}$ & $16.2 \pm 0.37^{\mathrm{t}}$ \\
\hline
\end{tabular}

"Values are means \pm S.E.M.

'Significantly difierent from Sed-25 group, $p<0.05$.

'Significantly different from Sed-25 group, $p<0.001$.

dSignificantly different from Sed-25 group, $p<0.02$.

$0.1<p>0.05$ vs. Sed-25 group.

'Significantly different from Wt-25, $p<0.001$.

sSignificantly different from Wt-25 and Sed-9, $p<0.001$.

nonmitochondrial contamination. Consistent with the similarity between experimental groups with respect to kinetic parameters (Table II), we have noted no structural differences between mitochondria isolated from the several groups.

\section{Muscle weights and protein yields}

During the 16-month period between 9 and 25 months, the wet weight of the gastrocnemius muscle decreased significantly $(-14 \%)$ (Table III). During the same period the total protein content of the muscles increased $15 \%$ and the protein proportion of the wet weight of the muscle increased $35 \%$ in the sedentary animals (Table III). Food restriction resulted in a significant lowering of both the wet weight and protein content of the gastrocnemius muscles of the sedentary elderly rat with no significant difference in the protein percentage. The wet weight of the muscle tended to increase with training with respect to the 25 -month-old sedentary group $(p<0.1$ and $>0.05)$ and significantly when compared to the weight control group $(p<0.001)$, reaching a level equivalent to that of the 9-month-old sedentary rat. The total protein of the muscle of the 25 -month-old trained animals was equivalent to that of the sedentary group of the same age but significantly greater than both the Wt-25 and the Sed-9 groups $(p<0.001)$. The percentage of protein in the muscle was lower in the trained group than in both the weight restricted group $(p<0.001)$ and the elderly sedentary group $(p<$ 0.001 ).

\section{DISCUSSION}

Since the original report of an increase in the oxidative capacity of skeletal muscle accompanying adaptation to prolonged endurance exercise [33], a good 
deal of biochemical information has appeared implicating mitochondrial oxidative metabolism in the responses to exercise and the loss of such activities and capacities during disuse atrophy [5]. Sufficient data now exist to support the conclusion that the elevated respiratory capacity of skeletal muscle in response to endurance exercise is due to an increase in the tissue density and size of mitochondria [34] rather than to an alteration of the kinetic characteristics of the mitochondrial regulatory mechanism $[9,10,11]$ (see also Table II this paper). A response of the adenine nucleotide translocase to endurance exercise has been noted [35], however.

A rather large body of evidence exists showing a general decline in the oxidative metabolism of skeletal muscle tissue with age (see refs. 2 and 36 for reviews). Some evidence also exists indicating that the oxidative capacity of skeletal muscle may be increased in the elderly animal in response to endurance training $[9,10,12,37,38]$. What is not clear, however, is whether the loss of oxidative capacity with age is a reflection of (1) a decrease in the mitochondrial population density of the tissue, (2) a decrease in the content of respiratory enzymes of individual mitochondria with little or no change in population density, (3) an increase in the number of respiratory enzyme molecules containing errors in their primary structure sufficient to render them ineffective, or (4) an increase in the fragility of the mitochondria resulting in fracture during homogenization and loss during isolation. The data presented herein bear on these, and other, questions.

Between the ages of 9 and 25 months, the wet weight of the gastrocnemius muscle of the rats in this study declined $14 \%$, a decline not apparent in the endurance trained group (Table III). The 25-month-old rats whose weights had been reduced by food restriction had still lighter gastrocnemius muscles. Contrary to the decrease in the wet weight of the muscle with age, the protein content increased both in terms of total protein and percentage of wet weight, possibly reflecting the increase in the content of collagen which occurs in skeletal muscle with age [39]. Despite the lower wet weight and total protein content of the muscle from the weight control group compared to the three other groups studied, the percentage of protein is highest in this group. This, also, may be a reflection of the accumulation of collagen in the aged muscle which, because of its high degree of intra- and intermolecular crosslinks, is conserved preferentially during weight loss resulting from food restriction. Conversely, both the wet weight and total protein of the muscles of the endurance trained rat were high while the percentage of protein was lower than both the Sed-25 and the Wt-25 groups. This may reflect a stimulation in the synthesis of contractile proteins and enzymes of aerobic pathways and a decrease of collagen in response to the increase in physical activity [4].

The data in Table I on the rates of substrate oxidations by gastrocnemius muscle homogenates and Fig. 2 on flavin levels of this muscle from the four groups of animals support the contention that the oxidative capacity of skeletal 
muscle decreases in the elderly. The large increases in the rates of substrate oxidations and flavin levels in the muscles of the endurance trained elderly animals demonstrate that, whatever the mechanism regulating such activity in the aging muscle, it is clearly reversible in the elderly as well as in the younger animal. It is noteworthy in this era of weight consciousness that, in general, the oxidative capacity, the wet weight, the total protein content, and the mitochondrial yield of the gastrocnemius muscle from the food restricted weight controlled group were the lowest of the four groups studied, demonstrating the importance of the difference between weight loss via sedentary caloric restriction (disuse atrophy) and caloric utilization through exercise. These data are of interest in view of the report [40] that food restriction early in the life of the rat, which leads to increased longevity, also decreases the fall in skeletal muscle oxygen consumption in elderly rats. The data reported in Table I show that such is not the case in elderly rats in which food restriction and accompanying weight loss start late in life.

It is of interest that, although the yield of mitochondria from muscle decreased with age and was elevated in the muscle of the elderly rat with exercise, the kinetic characteristics of the isolated mitochondria from the four groups of animals did not differ with respect to maximal rates of pyruvate oxidation (state 3 and + uncoupler), the adenylate control of respiration (respiratory control ratio, + oligomycin) or the efficiency of ATP synthesis (ADP/O). These observations are consistent with those reported by Hansford and Castro [13], Farrar et al. [12], and the original observation of Chen et al. [41]. It should be pointed out, however, that isolated mitochondria from skeletal muscle of elderly animals do catalyze beta-oxidation of fatty acids more slowly than mitochondria from younger animals [41]. Hansford [42] has shown that it is primarily lipid oxidation which declines in heart mitochondria in the aging rat. It is of interest that the largest increase in oxidative capacity resulting from endurance training of the elderly rat was with palmitoylcarnitine; its rate of oxidation in this 25 -month-old rat exceeded that of the muscle preparation from the 9-month-old rat (Table 1 ).

Although the enzymes involved in the oxidation of the substrates used in this study are localized in the mitochondrion, homogenates, instead of isolated mitochondria, were used to assay overall oxidative capacity of the muscle. This avoided the possibility of excluding a fraction of the mitochondria of the tissue in our assays due to loss during isolation, observed for liver [43] and heart [44] in elderly animals. In addition, the overall pathway from substrate to oxygen, instead of individual enzymic steps, has been used to assay oxidative capacity so as to obviate the possibility of inadvertently bypassing the rate limiting step(s) of the pathway of interest.

One goal of those studying aging is to identify means of shifting the aging curve from a general decline to a more rectilinear shape. In this context, at least in the laboratory rat and the human, many of the changes observed to accompany age are similar to those accompanying disuse atrophy [45]. The data reported herein 
and elsewhere suggest that a regular exercise program is able to reverse some of the age-related functional declines even if initiated late in the life of otherwise sedentary individuals. This is not to suggest, however, that an age does not exist beyond which the cell is genetically limited in its biochemical response to exercise since some evidence exists [46,47] for a "threshold age" [6], at least in mdents. Richardson and Cheung [48] have suggested that a general decline with age in gene expression, translation and transcription, resulting in a decrease in protein turnover, may lead to an age-related decrease in the response of the aged animal to stimuli and thus a lowering of induced enzyme synthesis. The results reported herein suggest that, at least up to the age of 21 months, rats of this SpragueDawley strain do respond to exercise by, most likely, synthesizing more functional mitochondrial assemblies in skeletal muscle. An alternative mechanism, accounting for changes in oxidative rates with ageing and exercise, should be considered which involves modifications in lipid composition and structural order, factors which regulate inner mitochondrial membrane fluidity. An increase in the state of order, and thus rigidity, of the hydrophobic phase of the inner mitochondrial membrane could limit the lateral movement and interaction of components of the electron transport chain. Since Vorbeck et al. [49] have reported just such changes in the lipid composition and ordered state of liver mitochondria from aged rats, this level of control deserves serious consideration as a contributing factor to mechanisms underlying the rate observations reported above.

\section{ACKNOWLEDGEMENTS}

This research received financial support from a Rackham Faculty Research Grant to R.E. Beyer, a Michigan Heart Association Postdoctoral Fellowship to J.W. Starnes, and the Cutcheon Fund of The University of Michigan Honors Program. We wish to acknowledge Ms. Sheila Cameron for her gentle handling of the elderly animals during their endurance training period and Mr. Rollin Gruschow for providing an environment in which our ageing colony is able to survive to an advanced age.

\section{REFERENCES}

1 I. Astrand, Aerobic work capacity in men and women with special reference to age. Acta Physiol. Scand. Suppl., 169 (1966).

2 D.R. Sanadi, Metabolic changes and their significance in aging. In C.F. Finch and L. Hayflick (eds.), Handbook of the Biology of Aging, Van Nostrand Reinhold, New York, 1977, pp. 73-98.

3 J. Örlander, K.-H. Kiessling, L. Larsson, J. Karlsson and A. Aniansson, Skeletal muscle metabolism and ultrastructure in relation to age in sedentary men. Acta Physiol. Scand., 104 (1978) 249-261.

4 R.E. Beyer, Regulation of connective tissue metabolism in aging and exercise: a review. In K.T. Borer, D.W. Edington and T.P. White (eds.), Future Issues in Exercise Biology, Human Kinetics, Champaign, 1983, pp. 85-99.

5 J.O. Holloszy and F.W. Booth, Biochemical adaptations to endurance exercise in muscle. Annu. Rev. Physiol., 38 (1976) 273-291. 
6 D.W. Edington, A.C. Cosmas and W.B. McCafferty, Exercise and longevity: evidence for a threshold age. J. Gerontol., 27 (1972) 341-343.

7 E. Retzlaff, J. Fontaine and W. Futura, Effect of daily exercise on life-span of albino rats. Geriatrics, 21 (1966) 171-177.

8 N.W. Shock, Physical activity and the "rate of aging". In A.P. Polednak (ed.), The Longevity of Athletes, C. C. Thomas, Springfield, 1979.

9 R.E. Beyer, R.T. Compton, III, D.W. Edington, M.A. Kwasman, R.J. Lipton, L.J. Ponte and J.W. Starnes. Age associated decline of skeletal muscle exergonic pathways: reversal with exercise. Age. 4 (1981) 138.

10 R.E. Beyer, D.W. Edington, J.W. Starnes, M. Kwasman and R.J. Lipton, Biochemical evidence for a training effect in aged animals. Med. Sci. Sports, 13 (1981) 81.

11 K.J.A. Davies, L. Packer and G.A. Brooks, Biochemical adaptation of mitochondria, muscle, and whole-animal respiration to endurance training. Arch. Biochem. Biophys., 209 (1981) 539-554.

12 R.P. Farrar, T.P. Martin and C.M. Ardies, The interaction of aging and endurance exercise upon the mitochondrial function of skeletal muscle. J. Gerontol., 36 (1981) 642-647.

13 R.G. Hansford and F. Castro, Age-linked changes in the activity of enzymes of the tricarboxylate cycle and lipid oxidation, and of carnitine content, in muscles of the rat. Mech. Ageing Dev., 19 (1982) 191-201.

14 J.W. Starnes, R.E. Beyer and D.W. Edington, Myocardial adaptations to endurance exercise in aged rats. Am. J. Physiol., 245 (Heart Circ. Physiol., 14) (1983) H560-H566.

15 R.J. Barnard and J.B. Peter, Effect of exercise on skeletal muscle. III. Cytochrome changes. J. Appl. Physiol, 31 (1971) $904-908$.

16 M.W. Makinen and C.-P. Lee, Biochemical studies on skeletal muscle mitochondria. I. Microanalysis of cytochrome content, oxidative and phosphorylative activities of mammalian skeletal muscle mitochondria. Arch. Biochem. Biophys., 126 (1968) 75-82.

17 R.E. Beyer and J.E. MacDonald, Inhibition of respiration in submitochondrial particles by uncouplers of oxidative phosphorylation. Arch. Biochem. Biophys., 137 (1970) 38-50.

18 J.E. Kuner and R.E. Beyer, An ultrastructural study of isolated rat skeletal muscle mitochondria in various metabolic states. J. Membrane Biol., 2 (1970) 71-84.

19 C. Watters, A one-step biuret assay for protein in the presence of detergent. Anal. Biochem., 88 (1978) 695-698.

20 R.E. Beyer, A rapid biuret assay for protein of whole fatty tissues. Anal. Biochem., 129 (1983) 483-485.

21 Y. Kaziro, S. Ochoa, R.C. Warner and J.-Y. Chen, Metabolism of propionic acid in animal tissues. VIII. Crystalline propionyl carboxylase. J. Biol. Chem., 236 (1961) 1917-1923.

22 O.H. Lowry, N.J. Rosebrough, A.C. Farr and R.J. Randall, Protein measurement with the Folin-phenol reagent. J. Biol. Chem., 193 (1951) 265-275.

23 I.B. Fritz and R.E. Beyer, Apparent respiratory control in uncoupled mitochondria. J. Biol. Chem., 244 (1969) 3075-3083.

24 R.W. Estabrook, Mitochondrial respiratory control and the polarographic measurement of ADP: O ratios. Methods Enzymol., X (1967) 41-47.

25 M.A. Lessler, Marco- and micro-oxygen electrode techniques for cell measurement. Methods Cell Physiol., 5 (1972) 199-218.

26 B. Chance and G.R. Williams, The respiratory chain and oxidative phosphorylation. In F.F. Nord (ed.), Advances in Enzymology, Vol. 17, Interscience, New York, 1956, pp. 65-134.

27 H. Adam, Adenosine-5'-diphosphate and adenosine-5'-monophosphate. In H.U. Bergmeyer (ed.). Methods of Enzymatic Analysis, Academic Press, New York, 1963, pp. 573-577.

28 R.A. Rao, S.D. Felton and F.A. Huennekens, Quantitative determination of mitochondrial flavins. Methods Enzymol., X (1967) 494-499.

29 W.B. McCafferty and D.W. Edington, Skeletal muscle and organ weight of aged and trained male rats. Gerontologia, 20 (1974) 44-46.

30 T.P. Singer, J. Salach, W.H. Walker, M. Gutman, P. Hemmerich and A. Ehrenberg, On the structure of the covalently linked FAD in succinate dehydrogenase. In H. Kamin (ed.). Flavins and Flavoproteins, University Park Press, Baltimore, 1971, pp. 607-621.

31 M.D. Gross, S. Harris and R.E. Beyer. The effect of streptozotocin-induced diabetes on oxidative 
phosphorylation and related reactions in skeletal muscle mitochondria. Horm. Metab. Res., 4 (1972) 1-7.

32 G.A. Brooks, K.J. Hittleman, J.A. Faulkner and R.E. Beyer, Temperature, skeletal muscle mitochondrial functions, and oxygen debt. Am. J. Physiol., 220 (1971) 1053-1059.

33 J.O. Holloszy, Biochemical adaptations in muscle. Effeits of exercise on mitochondrial oxygen uptake and respiratory enzyme activity in skeletal muscle. J. Biol. Chem., 242 (1967) 2278-2282.

34 P.D. Gollnick and D.W. King, Effect of exercise and training on mitochondria of rat skeletal muscle. Am. J. Physiol., 216 (1969) 1502-1509.

$35 \mathrm{M}$. Reichert, Die Wirking von Training und Belastung auf die Skelettmuskelmitochondrien. Med. Sport, 19 (1979) 225-230.

36 R.G. Hansford, Energy metabolism. In J.R. Florini (ed.), CRC Handbook of Biochemistry of Aging, CRC Press, Boca Raton, 1981, pp. 137-162.

37 H. Souminen, E. Heikken and T. Parkatti, Effect of eight weeks physical training on muscle and connective tissue of $M$. vastus lateralis in 69-year-old men and women. J. Gerontol., 32 (1977) 33-37.

38 R.E. Beyer, D.W. Edington, J.W. Starnes, R.T. Compton, M.A. Kwasman, R.J. Lipton and L.D. Ponte. Exercise induced restoration of age associated decline of exergonic activities in skeletal muscle. Gerontologist, 22 (1982) 167-168.

39 S. Mohan and E. Radha, Age-related changes in rat muscle collagen. Gerontologia, 26 (1980) 61-67.

40 R.J.M. McCarter, E.J. Masoro and P.Y. Byung, Rat muscle structure and metabolism in relation to age and food intake. Am. J. Physiol., 242 (Regulatory Integrative Comp. Physiol., 11) (1982) R89-R93.

41 J.C. Chen, J.B. Warshaw and D.R. Sanadi, Regulation of mitochondrial respiration in senescence. J. Cell. Physiol., 80 (1972) 141-148.

42 R.G. Hansford, Lipid oxidation by heart mitochondria from young adult and senescent rats. Biochem. J., 170 (1978) 285-295.

43 P.D. Wilson and L.M. Franks, The effect of age on mitochondrial ultrastructure. Gerontologia, 21 (1975) 81-94.

44 R.R. Murfitt and D.R. Sanadi, Evidence for increased degeneration of mitochondria in old rats. A brief note. Mech. Ageing Dev., 8 (1978) 197-201.

45 W.M. Bortz, II, Disuse and aging. J. Am. Med. Assoc., 248 (1982) 1203-1208.

46 E. Steinhagen-Thiessen, A. Reznik and H. Hilz, Negative adaptation to physical training in senile mice. Mech. Ageing Dev., 12 (1980) 231-236.

47 E. Steinhagen-Thiessen, A.Z. Reznick and H. Hilz, Positive and negative adaptation of muscle enzymes in aging mice subjected to physical exercise. Mech. Aging Dev., 16 (1981) 363-369.

48 A. Richardson and H.T. Cheung, The relationship between age-related changes in gene expression, protein turnover, and the responsiveness of an organism to stimuli. Life Sci., 31 (1982) 605-613.

49 M.L. Vorbeck, A.P. Martin, J.W. Long, Jr., J.M. Smith and R.R. Orr, Jr., Aging-dependent modification of lipid composition and lipid structural order parameter of hepatic mitochondria. Anch. Biochem. Biophys., 217 (1982) 351-361. 